\title{
Millennial environment chronology in Eastern Turkey calculated by the composition of laminated sediments from Van and Erchek adjacent Lakes
}

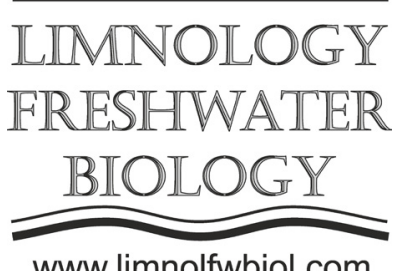

www.limnolfwbiol.com

\author{
Kalugin I.A. ${ }^{1 *}$, Meydan A. ${ }^{2}$, Darin A.V. ${ }^{1}$, Babich V.V. ${ }^{1}$, Markovich T.I. ${ }^{1}$, \\ Rogozin D.Yu. ${ }^{3}$
}

${ }^{1}$ Sobolev Institute of Geology and Mineralogy, Siberian Branch of the Russian Academy of Sciences. Prospekt akademika Koptyuga, 3, Novosibirsk, 630090, Russia

${ }^{2}$ Yüzüncü Yll University, Department of Geological Engineering, Van, 65000, Turkey

${ }^{3}$ Federal Research Center Krasnoyarsk Science Center of the Siberian Branch of the Russian Academy of Sciences. Akademgorodok Str., 50, Krasnoyarsk, 660036, Russia

\begin{abstract}
Turkish lakes Van and its satellite Erchek are located in a climate-sensitive area between the seas Black, Caspian and Mediterranean at the intersection of the atmospheric South-West flow and the Northern branch of the subtropical high-pressure belt. It is shown that the sediments of the adjacent lakes Van and Erchek at a distance of $20 \mathrm{~km}$ from each other, synchronously reacted to regional changes in the environment. This work contains high-resolution geochemical data on bottom sediments, which allowed converting them into time series of paleotemperature and lake level fluctuations on an annual-decadal scale. Physical and chemical conditions in model equilibrium systems (solid phase + water + gas) in the real range of external hydro-climatic factors were estimated based on the mineral composition of lake sediments of clay-carbonate type. To create a timescale, we used visual calculations of annual rhythms, as well as seasonal fluctuations in the content of elements. The time series of elements were synchronized with recent changes in weather conditions and with fluctuations in lake levels. So geochemical series calibrated on hydro-meteorological data were transformed by multiple regression approach into numerical reconstructions of natural parameters on a time scale. As a result, quantitative reconstructions of regional temperature were calculated: for Lake Van - 1300 and Erchek - 840 years ago, as well as Van level - 840 yrs.
\end{abstract}

Keywords: Lakes Van Erchek, sediment geochemistry, paleoenvironment, time series

\section{Introduction}

Turkish lakes Van and it's satellite Erchek are located within a sensitive climate region between the Black, Caspian and Mediterranean seas at the crossroads of the atmospheric south-western jet stream and the northern branch of the subtropical high pressure belt.

The geological information is widely known from many publications, including the data of the Van deep drilling project (ICDP), completed in 2010. One of the main accents of deep drilling was the considering about lake level fluctuations during glacial and interstadial periods. They conform two main lithotypes of bottom sediments 1) clayey clastic sediments of glacial intervals formed in the conditions of transgressions, and 2) carbonate bio-chemogenic deposits were typical in the stages of glacial-interglacial regressions of the lake. Recent sediments belong to second type deposits, which were studied as microfacies in accordance to local weather-climate oscillations.
The new data, such as elemental and mineral composition, fine structure, isotopic dating, the physical properties of the sediment, and their changes over the past thousand years were obtained with the use of the acknowledged optimal objects - varved sediments (Zolitschka et al., 2015). This work contains a new geochemical data on sediments allowed to transform it into time series and then to calculate paleotemperature and lake level change on annual-decadal scale.

\section{Methods}

Detailed lithological-geochemical study of bottom sediments was based on the original sampling of brackish lakes Van (core $120 \mathrm{~cm}$ in length) and Erchek $(110 \mathrm{~cm})$, eastern Turkey. The chemical composition of bottom sediments has been studied in two ways. $\mathrm{X}$-ray fluorescence analysis used series macroprobes after core cutting 5-20 mm. Moreover, micro scanning 


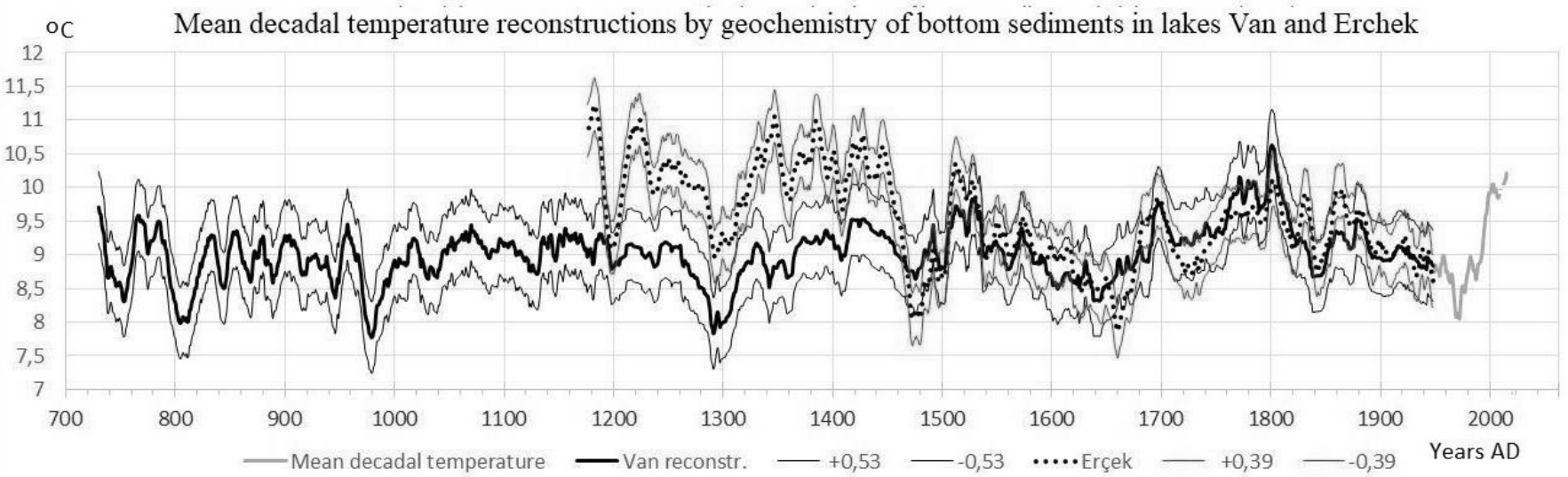

Fig.1. Reconstruction of mean decadal temperature in Eastern Anatolia by geochemistry of bottom sediments in lakes Van (longer record, bold line) and Erchek (shorter record, dotted line), grey line - instrumental data. . Mean decadal temperature on Van Lake: toC $=2,6419 \mathrm{E}-05 \mathrm{Ca}+0,1324864 \mathrm{Cu}+0,674955 \mathrm{Ga}+0,0649617$ As $+6,342357$, correlation coefficient $\mathrm{r}=0,93$ between instrumental meteodata and synchronous reconstructed time series on training interval; confidence interval $95 \%= \pm 0,53$ grad.C. On Erchek Lake: toC $=43,89644 \mathrm{Co} / \mathrm{Inc}+2,192067 \mathrm{E}-04 \mathrm{Ti}+0,1204825 \mathrm{Cu}-7,931993 \mathrm{E}-02 \mathrm{Br}+$ $2,247346, r=0,97$; conf. interval $95 \%= \pm 0,39$ grad.C.

- XRF SR (X-ray -fluorescence analysis on synchrotron radiation) with the measurement steps of $1 \mathrm{~mm}$ on solid preparates. Methods of visual counting the varves and annual oscillation of measured geochemical parameters have been applied to create a depth-age model as well as isotope ${ }^{137} \mathrm{Cs}$ analyses by gamma spectrometer.

\section{Results and discussion}

A fundamental similarity of the chemical composition and conditions of accumulation of the studied organics-clay-carbonate bottom sediments was revealed between both lakes. The most informative for correlation with the local climate were such geochemical proxies as: $\mathrm{Sr}$ and $\mathrm{Ca} / \mathrm{Sr}$, characterizing the carbonate constituent of the sediment, $\mathrm{Br}$ - as a sign of organic matter and $\mathrm{Rb}, \mathrm{K}, \mathrm{Zr}, \mathrm{Nb}$... - as elements of the silt - clay aluminosilicate mineral component, Mo and $\mathrm{Mo} / \mathrm{Mn}$ as an index of oxic-anoxic environmental condition.

A seasonal change in the accumulation of weather driving elements content was determined due to the high resolution micro-XRF SR analysis of annual layers in the solid preparates.

Stable mineral composition allowed the evaluation of physico-chemical conditions in natural equilibrium systems solid + water + gas at a given range of external hydroclimatic factors (Tretyakov et al., 2012). The mineral equilibria modeling confirmed the appearance of seasonal Sr- signal in the -annual cycle of sedimentation including ice cover period. According to equilibrium calculations, $\mathrm{Ca} / \mathrm{Sr}$ ratio in sediments was also used as a reliable proxy for lake salinity drop.

Visual counting of the thin sediment rhythms coincided with ${ }^{137} \mathrm{Cs}$ dating in justification a time scale. It indicated accumulation rates in the range of 1.35-1.8 mm per year (Erchek) and 0.89-1 (Van) in the last millennium. Element content time series were synchronized with recent changes of external climatic environments including the lake level fluctuations. Then geochemical series were transformed into climate units, using calibration on synchronous meteorological data. As a result, original quantitative reconstructions of the regional variations in climate were performed over the last millennium period with annual and decadal time resolution - Lake Van -1300 and Erchek 840 years ago (Fig. 1).

It was revealed that the sediments of the adjacent lakes in Turkey (Van and Erchek located at a distance of $20 \mathrm{~km}$ from each other) provided synchronous responses to regional environmental changes, which confirmed the reliability of the reconstructions. This result is quite expected, since the calibration was performed by the same meteorological data. So the restored annual air temperature turned up the same for both Turkish lakes. Disproportionately large volume of Lake Van water compared with the lake Erchek caused a certain shift in the temperature reconstruction of Van to the lower temperatures area on the chart, due to the thermostating of the Van waterbody. It should be assumed that a small volume of Lake Erchek water heated up faster than in Lake Van, which resulted in a more "high-temperature" position of the Erchek reconstruction. Thus, a direct sediment response to the water temperature changes rather than the atmospheric air is not excluded here.

Taking into account such similar response for both Lakes, the Van Lake level has been calculated by geochemistry in adjacent Lake Erchek sediments (Fig.2). Real Van amplitude measured in 1944-2015 years showed too small oscillations for correct estimations, but Erchek time series turned up suitable enough.

\section{Acknowledgments}

The work is done on state assignment of IGM SB RAS). It was supported by RFBR (Russia, project 15-5546001) and TUBITAK (Turkey, project 114Y825). 
The mean decadal level of Lake Van

m a.s.l. reconstructed by elements' content in bottom sediments of Lake Erchek

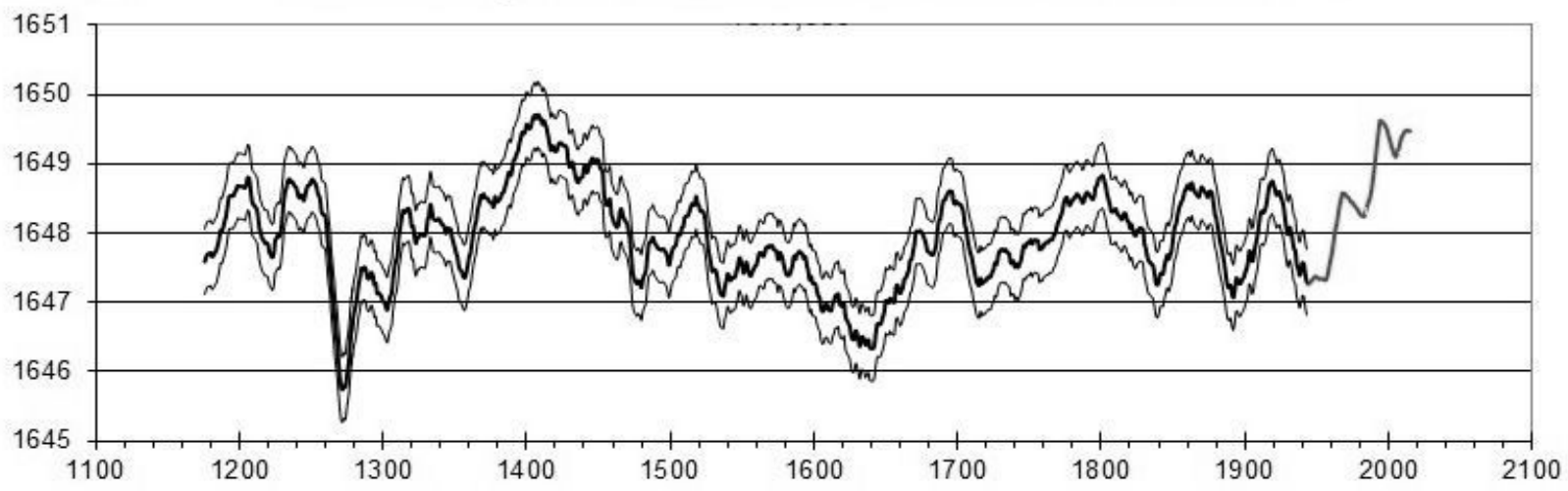

Fig.2. Reconstructed Van level, $\mathrm{m}$ a.s.l. $=2,95 * 10-3 \mathrm{Ti}-9,36 * 10-3 \mathrm{Sr}-0,46 \mathrm{Mo}-40,76 \mathrm{Mo} / \mathrm{Mn}+1649,39 ; \mathrm{r}=0,96$; confidence interval $= \pm 0,47$; optimal information weight, \%: Ti 31, Sr 38, Mo 15, Mo/Mn 16. Bold lines - reconstruction and confidence interval. Grey line - instrumental data.

\section{References}

Tret'yakov G. A., Kalugin I. A., Dar'in A.V. et al. 2012. Physicochemical conditions of seasonal carbonate precipitation in Shira Lake (Khakasia). Doklady Earth Sciences 446, Part 1: 1099-1101. DOI: 10.1134/S1028334X12090152

Zolitschka B., Francus P., Ojala A, E. K. et al. 2015. Varves in lake sediments - a review. Quaternary Science Reviews 117:141. http://dx.doi.org/10.1016/j.quascirev.2015.03.019 